\title{
Repurposing Diacerein and Pentoxifylline to Manage Para COVID-19 Syndrome
}

Mina Kelleni ${ }^{1}$

${ }^{1}$ Affiliation not available

October 20, 2021

\section{Hosted file}

Diacerein.pdf available at https://authorea.com/users/318758/articles/526200-repurposingdiacerein-and-pentoxifylline-to-manage-para-covid-19-syndrome

\section{Hosted file}

Repurposed diacerein Para COVID1.pdf available at https://authorea.com/users/318758/articles/ 526200-repurposing-diacerein-and-pentoxifylline-to-manage-para-covid-19-syndrome

\section{Hosted file}

Repurposed diacerein Para COVID.pdf available at https://authorea.com/users/318758/articles/ 526200-repurposing-diacerein-and-pentoxifylline-to-manage-para-covid-19-syndrome 